\title{
PRIOR GEOGRAPHIC MOBILITY AND JOB SEARCH LENGTH
}

\author{
Ernst Goss*
}

\section{Introduction}

Research into the unemployment problem has shown that there is a wide variation in the amount of time unemployed workers take to find jobs. The analysis of the causes of this variation has occupied a position of great importance in the development and implementation of national labor market and welfare policies. Many studies of this phenomenon have focused on the impact of unemployment insurance and other government transfer payments on the length of job search (Feldstein, 1975; Marston, 1975; Ehrenberg and Oaxaca, 1976). Other studies have concentrated on individual worker characteristics such as age, education level, and material and health status to explain the observed differences in this length (Nickell, 1979; Kooreman and Ridder, 1983; Folmer and Van Dijk, 1985).

Search theory suggests, however, that one of the most important variables influencing search duration is the amount of information about the labor market that a worker possesses prior to the start of his or her search. In previous studies, this stock of information has been proxied by worker job experience variables, such as the number of years an individual has been in the labor force, his or her education level and age, or whether he or she regularly visits a labor exchange.

These variables leave out another potentially important source of an unemployed worker's stock of information: whether or not the worker has worked in several spatially differentiated labor markets. This study proposed that knowledge of regional wage differentials and other market conditions give a worker with prior geographic mobility experience a better stock of information than one who has worked all of his or her work life in the same geographical location. It is proposed that this superior stock of information has a significant impact on the amount of time it takes an unemployed worker to locate and accept a job.

\footnotetext{
*Director, Center for Business and Economic Research; and associate professor, School of Business, Salisbury State University, Salisbury, Md.. The author gratefully acknowledges the contributions of Professor Niles Shoening and three anonymous referees.
}

\section{Prior Geographic Mobility and Search Duration}

Kau and Sirmans (1977) found that individuals with prior migration experience appear to be better able to form more accurate expectations of the characteristics of destination areas and are not deterred as easily as others by distance (a proxy for information costs). They hypothesize that one of the major differences between the repeat mover and the primary mover is the degree of uncertainty that each group faces. ${ }^{1}$

Other migration research has shown that workers who have moved once are more likely to move again due to their lower psychic costs (Vanderkamp, 1968; Schwartz, 19.73). Thus, at the beginning of any unemployment spell, a worker with prior migration experience may be more willing to search for a new job over a wider area and to accept a job offer in another labor market. Hence, from both theoretical job search literature and from previous empirical migration research, it appears likely that there is a link between prior geographic mobility and search duration. This link, if it exists, has not been explicitly accounted for in past research using typical worker experience variables.

If, as hypothesized, those with previous migration experience possess superior information about the job market to begin with, they will not have to move to another labor market in order to reduce their search time since this information can be used to search in the local market as well. It is proposed that this superior information provides the individual with a better idea of the dispersion of wage offers, both in the local and distant labor markets. ${ }^{2}$ The worker faced with uncertainty in the labor market calculates a subjective wage/offer distribution for the entire market from his expectations of wage rates and employment opportunities.

Following Stigler (1962), a worker with better information about labor market conditions will have a better idea about the value of additional job search whether the worker searches locally or nationally. This better information, according to the Stigler model, reduces the variance of the perceived wage distribution of potential jobs. Thus, better information reduces the maximum expected wage or reservation wage. With a lower reservation wage, those with better information can be expected to search for a shorter time period, ceteris paribus. 
Mathematically, assuming a normally distributed wage/offer function, and assuming that 100 percent of wage offers are included in the interval of $W \pm 3 \sigma$, the maximum expected wage offer $(\mathrm{Wm})$ a worker will encounter is approximately

$$
\overline{\mathrm{W}} \mathrm{m}=\mathrm{W}+3 \sigma,
$$

where $\sigma$ and $\bar{W}$ represent the standard deviation and mean wage offer, respectively, in the worker's subjective wage/ offer distribution.

Thus, $a$ priori, those with a larger variance in their subjective wage/offer distribution will compute a higher reservation wage or maximum wage offer. With a higher reservation wage, these workers can be expected to search for longer lengths of time, ceteris paribus.

Of course, in order for the reservation wage to equal the maximum expected wage, one must assume an infinite time horizon with no discounting. Since these two factors are likely, invariant to prior migration, when years of experience is accounted for explicitly, the introduction of a finite time horizon and discounting would serve only to complicate the derivation while yielding the same conclusion-those with less information or more uncertainty regarding the wage offer distribution will likely search for longer periods of time, ceteris paribus.

Since it is hypothesized here that one of the prime distinguishing features of the prior migrant is less uncertainty and more informed decision making, the variances in their perceived wage offers will be lower than for the worker who has not moved previously. Assuming the marginal cost of search is invariant to prior migration experience, the unemployed worker with prior migration experience would be expected to search for a shorter period of time, ceteris paribus. ${ }^{3}$

Given the precding factors, one expects the Prior variable to be negatively related to search duration, and this relationship is expected to hold, even if a worker searches in the local labor market only (holding radius of search constant).

Of course, the strong positive relationship between prior migration experience and current migration has been well-documented in the migration literature, and this geographic mobility could be expected to reduce search time even further. Thus, to measure the impact of prior migration on search time, one must hold the radius of search constant.

A model developed by Schwartz (1976) prodvides a theoretical connection between search duration and area searched. In his model, Schwartz assumes that each worker, whether employed or unemployed, faces a tradeoff between the radius over which he or she searches for a job and the time it takes to find an acceptable wage offer.

A worker may act to minimize search time by expanding the search radius or minimize the search radius (and increase the probability of finding a job locally) by increasing the time spent searching. This relationship follows simply from the assumption that increasing the radius searched increases the number of available jobs within a given occupation.

By searching a larger area and finding a job in another labor market, the worker has increased the number of available jobs, thus decreasing search time. The negative relationship between the probability of migration and duration of job search has been tested empirically and substantiated (Goss and Schoening, 1985). Consequently, it is important to hold the radius of search constant if one wishes to measure the impact of prior migration on the length of job search.

According to the preceding discussion, the following regression model will be tested empirically, holding the radius of job search constant:

$$
\mathrm{T}=\mathrm{f}(\text { Prior, Other }),
$$

where $T$ equals the search time incurred by an unemployed worker to find and accept a suitable job during the period and Prior represents a variable to account for prior migration experience. "Other" variables, which have been found to affect job search time and will be included in this analysis, are education, years of labor market experience, ratio of transfer income to work income, and the unemployment rate in the local area.

Given a particular search radius, the probability of finding a job for which the worker is qualified is dependent on the density of job openings. The density of these job openings is also a function of the worker's experience and education. This functional relationship between the density of job openings and the education and experience of the worker follows from the occupational switching behavior of the better educated and/or more experienced worker.

According to Schwartz (1976), the economic feasibility of switching occupations declines with increasing education or work experience. This relationship between occupational switches and the education and experience of the worker can be formulated from the recognized relationship between occupation-specific skills and occupational mobility. Since formal education and experience usually provide skills that are specific to an occupation, higher levels of education and/or experience discourage occupational switches for the worker due to the loss of returns to the individual's educational investment or to the worker's on-the-job training.

Thus, the worker who is better educated and/or more 
experienced will resist accepting jobs in which the returns to his or her accumulated skills are lost. According to Schwartz, these workers will observe a lower density of job openings given a radius of job search and will widen their area of search or lengthen the amount of time they spend searching in order to increase the available jobs. Thus, education and experience are both expected to be positively related to search time.

The ratio of unemployment compensation to work income has been found to be an important variable explaining job search time of the unemployed (Nickell, 1979). The higher the ratio of non-work benefits to work benefits, the longer search time expected for the unemployed worker, ceteris paribus. Thus, the ratio of transfer income (which includes unemployment compensation) to work income would be expected to positively affect the job search time of the unemployed.

Relative job opportunities in the local labor market are expected to have a significant impact on the length of job search by the unemployed (Kooreman and Riddler, 1982). Unemployed workers in areas experiencing high levels of unemployment are expected to experience a longer length of job search, ceteris paribus. Thus, a positive relationship is expected between search time and relative unemployment in the local area.

\section{Empirical Results}

\section{The Data}

This study employed the Panel Study of Income Dynamics to test empirically the previously discussed hypothesis. The sample extracted from the PSID includes only those who were in the labor force, unemployed, and searching for working at some time in 1981 . This study used 1981 as the year of analysis, since this was the latest year for which values for all variables in the model were available. Descriptive statistics of the sample are contained in Table 1.

\section{The Model}

Search time is postulated to be a function of the following variables:

$$
\mathrm{T}=\mathrm{f} \text { (College, YrExp81, RatioTr, URate81, Prior), }
$$

where

$$
\begin{aligned}
& \text { T = length of time searching for } \mathrm{a} \text { job } \\
& \text { College }=\mathrm{a} \text { binary variable equal to one if the } \\
& \text { YrExp81 = number of years of full-time labor }
\end{aligned}
$$

Table 1

Data Set Statistics by Prior Mobility Experience

\begin{tabular}{lccc}
\hline \hline & $\begin{array}{c}\text { Those with no } \\
\text { Prior Moves }\end{array}$ & $\begin{array}{c}\text { Prior } \\
\text { Movers }\end{array}$ & All \\
\hline Number of Observations & 192 & 76 & 12.03 \\
Mean Weeks of Job Search before Job Found & 19.40 & 5 & 17.31 \\
Number of College Graduates & 10 & 11.28 & 11.38 \\
Mean Years of Education & 11.42 & 13.97 & 11.49 \\
Mean Years of Experience & 10.51 & $8.0 \%$ \\
Mean Unemployment Rate in Local Labor Market & $7.9 \%$ & $7.9 \%$ \\
\hline
\end{tabular}




\section{Regression Results}

As stated earlier, the radius of search is an important variable affecting the length of job search. However, due to the lack of a variable in the data set which adequately measures the radius of search for the unemployed, the sample was limited to those workers who stated that they did not intend to move in order to locate an acceptable job. To further insure that the radius of search is held constant, the analysis will be performed only on those who did not move during the analysis period (1981 state of residence equals the 1982 state of residence). Results from regressing search time on the independent variables discussed earlier using ordinary least squares is reported in Table 2.

As depicted in Table 2, the variable of interest, Prior, is statistically different from zero at the 98 percent level of confidence and is negatively related to search time, as hypothesized. In terms of relative effect on the duration of search (elasticity), the variable Prior ranks second only behind the variable RatioTr.
Survival Analysis

In order to investigate further the relationship between prior georgraphic mobility and job search time, the date was used as input to a survival function. The computation of the survival function is based on the actuarial method described by Berkson and Gage (1950). The results from this analysis are depicted in Table 3. The estimated probabilities are conditional on the individual not finding a job during the previous intervals.

Except for the intervals of 0-3 weeks and 24-27 weeks, those with prior migration experience are more likely to find a job during every interval than those with no prior migration experience. This provides further support for the hypothesis of this study.

The findings contained in Tables 2 and 3 contrast with the results expected from the model developed by Schwartz. In his model, search time can be reduced only by searching over a wider area and, by inference actually moving if a job in a distant location is found. According to the findings of this research, those with prior geographic mobility will experience shorter periods of unemployment, even when the search radius is held constant.

Table 2

Regression of Search Time on Independent Variables

Dependent Variable $=\mathrm{T}$

\begin{tabular}{|c|c|c|}
\hline Variable & Coefficient & Elasticity \\
\hline Intercept & $\begin{array}{l}18.8601^{*} \\
(5.7092)\end{array}$ & \\
\hline College & $\begin{array}{c}-2.9671 \\
(7.5674)\end{array}$ & -0.0161 \\
\hline YrExp81 & $\begin{array}{c}0.1709 \\
(0.1860)\end{array}$ & 0.0386 \\
\hline RatioTr & $\begin{array}{c}1.1898^{*} \\
(0.0661)\end{array}$ & 0.7396 \\
\hline URate81 & $\begin{array}{c}-0.5661 \\
(0.7265)\end{array}$ & -0.0358 \\
\hline Prior & $\begin{array}{r}-9.4480 * \\
(3.8905)\end{array}$ & -0.1007 \\
\hline
\end{tabular}

*Figures are significant at the 98 percent level of confidence.

Standard errors are listed in parentheses.

Number of Observations: 268

$\mathbf{R}^{2}=0.56$ 
Table 3

Probability of Finding a Job During Interval

(Given Unemployed at Beginning of Interval)

\begin{tabular}{ccc}
\hline \hline Length of Search & $\begin{array}{c}\text { Those with Prior } \\
\text { Migration Experience }\end{array}$ & $\begin{array}{c}\text { Those with No Prior } \\
\text { Migration Experience }\end{array}$ \\
\hline 0-3 weeks & 0.0607 & 0.0625 \\
4-7 weeks & 0.0547 & 0.0370 \\
8-11 weeks & 0.0446 & 0.0435 \\
12-15 weeks & 0.0543 & 0.0326 \\
16-19 weeks & 0.0467 & 0.0160 \\
20-23 weeks & 0.0231 & 0.0216 \\
24-27 weeks & & \\
28-31 weeks & 0.0345 & 0.0362 \\
32-35 weeks & 0.0192 & 0.0189 \\
\hline \hline
\end{tabular}

These results are also in opposition to those of Polachek and Horvath (1977). In their model, Polachek and Horvath propose that those with prior migration experience have more knowledge of distant labor relative to the local labor market. It is this ratio of "information," they contend, that is an important determinant of the worker's probability of migration. Those who have not moved previously have much better information on the local labor market relative to distant labor markets and thus are less mobile. The empirical results from this study do not support this separation of labor markets into distant and local, according to prior migration experience.

\section{Conclusion}

The prior migration variable appears to be picking up some facet of labor market information that other work experience variables included in past studies, such as age or education levels, omit. The effect of prior migration on search time appears to operate independent of whether a worker actually migrates to another labor market or not.

These results appear to predict that a labor market made up of a high proportion of prior migrants, or one that has experienced high levels of immigration from other labor markets, will exhibit lower average unemployment rates, ceteris paribus.

\section{Notes}

'Kau and Sirman (1977), as others (See Scholttman and Herzog (1981) and DaVanzo (1976)), define prior migrants as those individuals living in a state, at the time of the survey, different from the state in which they were born or in which they grew up.

2Of course, the use of Kau and Sirman's definition for prior migrants could result in the inclusion in the prior migrants category of individuals who may have worked in only one labor market.

${ }^{3} \mathrm{~A}$ competing, non-economic hypothesis might be: people who move more often are more impulsive about everything, including job selection.

\section{References}

Berkson, J., and R. Gage. "Calculation of Survival Rates for Cancer." Proceedings of the Mayo Clinic. 25 (1950).

DaVanzo, J. "Differences between Return and Non-return Migration: An Econometric Analysis." International Migration Review. 10 (Spring 1976).

Ehrenberg, X., and R. L. Oaxaca. "Unemployment Insurance, Duration of Unemployment, and Subsequent Wage Gain." The American Economic Review. 66 (1976). 754-766.

Feldstein, M. "Umemployment Policy after the Recession." Discussion Paper No. 441. Cambridge, Mass.: Harvard University, October 1975.

Folmer, H., and J. van Dijk. "Differences in Characteristics Between Unemployed with Different Spells of Unemployment." Paper presented at Southern Regional Science Association Meeting, Washington, D.C., May 9-11, 1985.

Goss, E. P., and N. C. Schoening. "Search Time, Unemployment and the Migration Decision." Journal of Human Resources. (Fall 1984). 570-579.

Kau, J., and C. F. Sirmans. "The Influence of Information Costs and Uncertainty on Migration: A Comparsion of Migrant Types." Journal of Regional Science. 17:1 (1977). 89-96.

Kooreman, P., and G. Ridder. "The Effects of Age and Unemployment Percentage on the Duration of Unemployment." 
European Economic Review. 20 (1982). 45-57.

Marston. S. T. "The Impact of Unemployment Insurance on Job Search." Brookings Papers on Economic Activity. (1975). 13-60.

Nickell, S. "Estimating the Probability of Leaving Unemployment." Econometrica. 47:5 (1979). 1249-1264.

Polachek, S. W., and F. W. Horvath. "A Life Cycle Approach to Migration: Analysis of the Perspicacious Peregrinator." 1 (1977). 103-149.
Schlottman, A. S., and H W. Herzog. "Employment Status and the Decision to Migrate." Review of Economics and Statistics. 63 (1981). 590-598.

Schwartz, A. "Migration, Age, and Education." Journal of Political Economy. 84 (August 1976). 701-719.

"Interpreting the Effect of Distance on Migration." Journal of Political Economy. 81 (September/ October 1973). 1153-1169.

Stigler, G. J. "Information in the Labor Market." Journal of Political Economy. 5:2 (October 1962). 94-105. 